LII.-On Samarium and its Compounds.

By Prof. P. T. Cleve, Hon. Member of the Chemical Society.

InTRODUCTION.

IN the year 1878 Delafontaine found, on examining impure didymia, extracted from samarskite, some new absorption-bands, which did not belong to didymium but to an unknown element of higher atomic weight. He named this metal Decipium. Some time later Lecoq de Boisbaudran found also in the fractions, rich in didymia, which were extracted from samarskite, a new oxide, distinguished by its absorption-spectrum and by peculiar spark-lines. The oxide was tbrown down with ammonia before that of didymium. He called the metallic radical Samarium, and described more exactly than Delafontaine its absorption-spectrum. In March, 1880, Delafontaine published in the Bibliothèque universelle de Genève a paper "On the Atomic Weight and the Compounds of Decipium." The atomic weight was found to be 114, if the oxide be $\mathrm{RO}\left(=171\right.$ if $\mathrm{R}_{2} \mathrm{O}_{3}$ ). The salts were colourless and the sulphate less soluble than the sulphate of didymium. Shortly afterwards Marignac published his researches on the earths which in the samarskite accompany terbia, and found an oxide, named $\mathrm{Y} \beta$, distinguished by its yellow salts, its spectrum of absorption agree- 
ing with that of samarium. The atomic weight of the metal was found, as a maximum $99 \cdot 6$, if the oxide be $\mathrm{RO}\left(=179 \cdot 4\right.$ if $\mathrm{R}_{2} \mathrm{O}_{3}$ ), thus differing widely from the figures given by Delafontaine. The latter has more recently found that the decipia of 1878 could be split up into an oxide without absorption-spectrum, for whose radical, of the atomic weight 117 (or 171 if $\mathrm{R}_{2} \mathrm{O}_{3}$ ) be reserved the name of decipium, and another oxide with the spectrum described by Lecoq de Boisbaudran. He adopted the name of samarium for the metal which has as a maximum the atomic weight 101 (or 151.5 if $\mathrm{R}_{2} \mathrm{O}_{3}$ ).

\section{Method of Extraction.}

The raw material, which I used for extracting the oxide of samarium, consisted principally of a mixture of almost all the rare oxides of the earth-metals, which were obtained from Dr. Paijkull, in Stockholm, and said to be derived from orthite found at Arendal in Norway. As the matter, ahout 10 kilos., contained almost 10-12 per cent. thorina, it may be assumed that a considerable quantity of thorite may have been mistaken for orthite. The mixture of earths was mixed with nitric acid and heated in china basins till it began to give off red vapours. After cooling, the mass was treated with water, which left undissolved a large quantity of basic nitrates, principally of cerium and thorium. These basic nitrates were insoluble in saline liquids, but dissolved in pure water, forming opalescent solutions. They were separated by decantation and filtering, and washed as long as the liquid went clear through the filter. The basic salts were mixed with strong sulphuric acid, and the solution of the sulphates in cold water was precipitated with large quantities of hot water, by which operation most of the cerium was separated as basic sulphate.

The solution was then precipitated with caustic soda and the hydrate, principally of thorium, dissolved in diluted sulphuric acid. On evaporating off the solution, large and bulky masses of thorium sulphate were obtained. The oxides, which remained in the motherliquors, were transformed into nitrates and added to the solution of nitrates obtained by the first operation. These nitrates were evaporated, and the residuum was heated in platinum basins till it began to give off red vapours. On treating the heated mass with water, a solution free from cerium and thorium was obtained.

By this treatment also considerable quantities of the nitrates of the more positive metals, yttrium, didymium, \&c., were decomposed, and separated together with the thorium and cerium, and to complete the separation, the basic nitrates were once again and carefully treated in the same manner. The solutions free from the oxides of cerium and thorium, or containing only small traces of these oxides, were 
precipitated with potassium sulphate with the view of separating the cerium-and yttrium-oxides, of which the former were (incompletely) precipitated, and the latter (incompletely) retained in the solution.

The yttria earths (about 700 grams) were transformed into nitrates and subjected to the usual melting-process, for separation of erbia from yttria, terbia, and didymia, which offer greater resistance to the action of heat. From the basic nitrates first obtained a small quantity (about $1.5 \mathrm{gram}$ ) of scandium oxide was separated.)* They contained also a very small quantity of thulium, some erbia and ytterbia, and a considerable portion of holmia. The fractions containing yttria and didymia were saturated with potassium sulphate, and this precipitate was added to the similar precipitate formerly obtained. These difficultly soluble double sulphates were decomposed with boiling potash-ley, and the hydrates dissolved in diluted sulphnric acid were again treated with potassiam sulphate. In the solution there then remained considerable quantities of terbia (about 200 grams impure earth). The precipitate was converted into nitrate and its solution evaporated. The residue was then heated to partial decomposition in order to separate the last remaining traces of thorium and cerium.

The soluble nitrates thus obtained, which contained principally didymium and lanthanum, but also samarium, terbium, yttrium, \&c., were mixed with impure didymium, extracted from varions minerals as cerite, gadolinite, keilhauite, \&c., and then subjected to partial precipitation with cold dilute ammonia. The last fractions contained much lanthannm, which was separated partly by the Mosander method, and partly by precipitation with ammonia. No oxide intermediate between that of lanthanum and that of didymium could be obtained, although I sacrificed much time in searching for such an oxide. The first precipitations were repeatedly treated in the same manner with dilute ammonia. In this way I obtained several fractions containing both terbia and didymia (samarium, \&c.). They were again treated several times with sulphate of potash.

The slightly soluble double sulphates were now decomposed, and the solution of the hydrates in nitric acid was repeatedly precipitated with ammonia. I obtained finally the following fractions :-

1 : about 67 grams light-coloured oxides, whose solution was very little coloured, but showed, besides the spectrum of samarium, also the spectrum of didymium. Atomic weight $R^{\prime \prime \prime}=149-150$.

$\begin{array}{rlrlrl}2: \text { about } 4 \text { grams oxide; } & & \text { at. w. R } & =148 \\ 3: & 1 \cdot 7 & , & , & & =146 \cdot 2 \\ 4: & 6 & , & & & =143 \cdot 7\end{array}$

* No scandium could be obtained from the precipitate with sulphate of potiskium. 
5 : about 150 grams oxide;

6 :

,9

$$
\text { at. w. } \begin{aligned}
\mathrm{R} & =142 \cdot 7 \\
& =142 \cdot 3
\end{aligned}
$$

The sixth fraction was subjected to partial precipitation with ammonia, but the atomic weight of the four fractions thus obtained was still found to be $142 \cdot 3$.

This is a proof of the correctness of my latest determinations of the atomic weight of didyminm, which gave the same numbers. No lanthanum was present in these fractions. As the fractions intermiediate between the pure or almost pure didymium and the samarium are only trifling, there is very little probability of finding any unknown element intermediate between samarium and didyminm.

The 67 grams of earths containing the principal quantity of samarium were now subjected to the same treatment with dilute ammonia, until the absorption-spectrum of didymium was completely eliminated. The oxides freed from didymium were far from pure samarium oxide, and I was therefore obliged to precipitate their solutions with potassium sulphate.

At first I several times used solutions with 2 per cent. oxide, and later with only $\frac{1}{2}$ per cent. Terbia and other oxides ( $\mathrm{Y} \alpha$, decipium) were thus eliminated together with much samarium oxide. The treatment with potassium sulphate was continued until the oxide, which remained in the solution, had the same molecular weight as the oxide thrown down, or $\mathrm{R}^{\prime \prime \prime}=150$.

A considerable quantity of samaria was separated at the same time as terbia and $Y \alpha$, for which reason $I$ was obliged to subject these oxides to the same treatment, whereby I finally obtained the fractions used for the atomic weight determinations $\mathrm{A}$ and $\mathrm{B}, \mathrm{A}$ being oxide left in the solution, and $\mathrm{B}$ precipitated as double sulphate.

I have described this method, as long experience has conrinced me that the coarse separation of all the rare earths may be most conveniently effected thereby.

\section{Atomic Weight of Samarium.}

The samarium oxide, obtained as above described, was purified by treatment with sulphuretted hydrogen, repeated precipitation of the solution with ammonia, and finally in acid solution with pure oxalic acid. The oxide obtained by calcination of the oxalate was dissolved in pure nitric acid, and by precipitation with freshly distilled ammonia, divided into four fractions, I, II, III, IV. These were transformed into oxalate and oxide. The four fractions thus obtained were subjected to atomic weight determinations in the usual way, by solution in uitric acid, addition of sulphuric acid, and estimation of the sulphates. The fractions $A$ and $B$ were obtained, as stated in the fore- 
going section, from the samarium oxide which remained in the solution of potassium sulphate.

The atomic weight determinations gave the following results :-

\begin{tabular}{|c|c|c|c|c|}
\hline & Oxide & \multicolumn{3}{|c|}{ Per cent. of oxide } \\
\hline & $\mathrm{Sm}_{2} \mathrm{O}_{3}$ & Sulphate. & in the sulphate. & At. $w .\left(\mathrm{SO}_{3}=80\right.$. $)$ \\
\hline 1 . & 1.6735 & $2 \cdot 8278$ & $59 \cdot 180$ & \\
\hline II. & $1 \cdot 9706$ & $3 \cdot 3301$ & $59 \cdot 175$ & $149 \cdot 940$ \\
\hline III. & $1 \cdot 1122$ & $1 \cdot 8787$ & $59 \cdot 201$ & $150 \cdot 120$ \\
\hline IV. & $1 \cdot 0634$ & $1 \cdot 7966$ & $59 \cdot 190$ & $150 \cdot 045$ \\
\hline A. & 0.8547 & $1 \cdot 4440$ & $59 \cdot 190$ & $150 \cdot 04.5$ \\
\hline B. & 0.7447 & $1 \cdot 2583$ & $59 \cdot 183$ & $150 \cdot 000$ \\
\hline
\end{tabular}

As a mean of these six closely agreeing experiments, the atomic weight is 150.021 , or in round numbers 150 . In the calculation I have supposed the oxide to be $\operatorname{Sm}_{2} \mathrm{O}_{3}$, which follows beyond doubt, from its chemical properties, that is from the composition of the chloroplatinate, of the samarium and ammonium sulphate, and of the selenite. Whether samarium gives other oxides besides $\mathrm{Sm}_{2} \mathrm{O}_{3}$ is a point which $I$ have not yet determined. As to its position in the system of Mendelejeff, I think it may most probably be placed in the 8th group, on the 8th line, where there is a gap for a group of unknown elements.

\section{Spectrum of Samarium.}

The salts of samarium are distinguished by a peculiar spectrum, composed of several bands, among which four in the blue part of the spectrum are most characteristic. The absorption-spectrum bas been examined by Lecoq de Boisbaudran and by Thalén. The latter used a solution of the nitrate prepared by myself.

Both found about the same bands, viz. :-

\begin{tabular}{|c|c|c|}
\hline & Wave-length acc & rding to \\
\hline Numbers. & $\begin{array}{c}\text { Lecoq de } \\
\text { Boisbaudran. }\end{array}$ & Thalén. \\
\hline I. & 559 & $556-559$ \\
\hline II. & $551-500$ & $501 \cdot 5-497$ \\
\hline III. & 489 (indistinct) & - \\
\hline IV. & $486-474$ & $486-472$ strong \\
\hline $\mathrm{V}$. & $464-463$ & $466^{\circ}-460$ strong \\
\hline VI. & - & $445-437$ not strong \\
\hline VII. & 417 & $418 \cdot 5-415$ \\
\hline VIII. & $400 \cdot 75$ & 409 (limit not visible) \\
\hline
\end{tabular}

The intensity of the absorption is not very great, so that the absence of these bands in didymium salts cannot be regarded as a sure test for the absence of samarium. 
The spark-spectrum of samarium has been examined by Professor Thalén, who will soon publish his results. He has found about 150 lines scattered over the whole spectrum, except the red part. They are all of little intensity. Many among these lines were mapped by him in connection with his examination of the spectrum of didymium in the year 1873 (Kongl. Svenska Vetensk.-Akad. Handlingar, t. xii, No. 4). The didymia, which I regarded at that time as pure, was thus a mixture of didymia and samaria, which is also apparent from the atomic weight 147 , instead of $142 \cdot 3$.

\section{Compounds of Samarium.}

Oxide of Samarium, $\mathrm{Sm}_{2} \mathrm{O}_{3}$, is a white powder, with a scarcely perceptible yellowish tint. If yellow it contains terbia. It is easily soluble in acids, and gives with them salts whose solutions are intensely yellow. The crystallised salts are topaz-coloured, but in the state of powder they are white, with a yellowish tint.

The hydroxide is a gelatinous, white, or indistinctly yellowish precipitate, insoluble in alkalis. It is a stronger basic than yttria, but not so strong as didymia.

Chloride of Samarium, $\mathrm{SmCl}_{3}+6 \mathrm{H}_{2} \mathrm{O}$, crystallises in large tabular crystals, which are deliquescent. Pressed between paper, as were all the following salts, it gave by analysis the following results :-

0.5708 gram gave 0.6647 gram $\mathrm{AgCl}$.

0.7375 gram gave $0.3513 \mathrm{Sm}_{2} \mathrm{O}_{\imath}$, precipitated as oxalate.

$\begin{array}{ccc}\text { In per cent. } & \text { Calc. } & \text { Found. } \\ \text { Sm } \ldots \ldots \ldots \ldots & 41 \cdot 15 & 41 \cdot 06 \\ \text { Cl } \ldots \ldots \ldots \ldots & 29 \cdot 22 & 28 \cdot 79\end{array}$

Chloroplatinate of Samarium, $\mathrm{SmCl}_{3}, \mathrm{PtCl}_{4}+10 \frac{1}{2} \mathrm{H}_{2} \mathrm{O}$, crystallises over sulphuric acid in orange-coloured prisms, which are deliquescent, and lose at $110^{\circ} 8.71$ per cent. $\mathrm{H}_{2} \mathrm{O}(4 \mathrm{mols} .=9 \cdot 20)$.

0.5775 gram gave 0.3611 gram $\mathrm{Sm}_{2}\left(\mathrm{SO}_{4}\right)_{3}+\mathrm{Pt}$, which left on washing with water $0 \cdot 1402$ gram Pt.

$\begin{array}{ccc} & \text { Calc. } & \text { Found. } \\ \text { Pt } \ldots \ldots \ldots \ldots & 24 \cdot 92 & 24 \cdot 22 \\ \text { Pt }+\mathrm{Sm}_{2} 3 \mathrm{SO}_{4} \ldots & 62 \cdot 49 & 62 \cdot 53\end{array}$

Platinocyanate of Samarium, $2 \mathrm{Sm}(\mathrm{CN})_{3}+3 \mathrm{Pt}(\mathrm{CN})_{2}+18 \mathrm{H}_{2} \mathrm{O}$, obtained by double decomposition of the barium salt with the sulphate, crystallises in well-developed yellow prisms, which reflect blue light. It is unchangeable in the air, and loses at $110^{\circ} 16.33$ per cent. $\mathrm{H}_{2} \mathrm{O}$ (14. mols. $=16 \cdot 57)$. 
0.6963 gram gave 0.5396 gram $\mathrm{Sm}_{2} 3 \mathrm{SO}_{4}+\mathrm{Pt}$, which left by washing with water $0 \cdot 2694$ gram Pt.

$$
\begin{array}{ccc} 
& \text { Calc. } & \text { Found. } \\
\mathrm{Pt} \ldots \ldots \ldots \ldots & 38 \cdot 46 & 38 \cdot 69 \\
\mathrm{Pt}+\mathrm{Sm}_{2} 3 \mathrm{SO}_{4} . & 77 \cdot 12 & 77 \cdot 49
\end{array}
$$

Nitrate of Samarium, $\mathrm{Sm}\left(\mathrm{NO}_{3}\right)_{3}+6 \mathrm{H}_{2} \mathrm{O}$, crystallises in easily soluble prisms of pale yellowish colour.

1.0969 gram left by ignition 0.4274 gram $\mathrm{Sm}_{2} \mathrm{O}_{3}$.

$$
\begin{array}{lll} 
& \text { Calc. } & \text { Found. } \\
\mathrm{Sm}_{2} \mathrm{O}_{3} \ldots \ldots \ldots & 39 \cdot 19 & 38 \cdot 96
\end{array}
$$

Acetate of Samarium, $\mathrm{Sm}\left(\mathrm{C}_{2} \mathrm{H}_{3} \mathrm{O}_{2}\right)_{3}+4 \mathrm{H}_{2} \mathrm{O}$, forms short, welldeveloped prisms, moderately soluble in water.

0.7886 gram lost by $110^{\circ} 0.1393$ gram $\mathrm{H}_{2} \mathrm{O}$, and gave by ignition 0.3444 gram $\mathrm{Sm}_{2} \mathrm{O}_{3}$.

0.8688 gram lost 0.1546 gram $\mathrm{H}_{2} \mathrm{O}$, and gave 0.3802 gram $\mathrm{Sm}_{2} \mathrm{O}_{3}$.

$$
\begin{array}{cccc} 
& & \text { Calc. } & \text { Found. } \\
\mathrm{Sm}_{2} \mathrm{O}_{3} & \ldots & 43 \cdot 61 & 43 \cdot 67-43.76 \\
\mathrm{H}_{3} \mathrm{O} \ldots & \ldots & 18.05 & 17 \cdot 66-17.79
\end{array}
$$

Sulphate of Samarium, $\mathrm{Sm}_{2}\left(\mathrm{SO}_{4}\right)_{3}+8 \mathrm{H}_{2} \mathrm{O}$, obtained by evaporating on the water-bath a solution of the nitrate mixed with sulphuric acid, forms well-developed brilliant crystals, much less soluble in water than sulphate of didymium.

\begin{tabular}{|c|c|}
\hline $\mathrm{Sm}_{2} \mathrm{O}_{3} \ldots$ & $\begin{array}{c}\text { Calc. } \\
39 \cdot 86\end{array}$ \\
\hline $\mathrm{H}_{2} \mathrm{O} \quad \ldots \ldots$ & $16 \cdot 49$ \\
\hline
\end{tabular}

0.8966 gram lost by careful heating 0.1763 gram $\mathrm{H}_{2} \mathrm{O}$.

0.8240 gram lost 0.1620 gram $\mathrm{H}_{2} \mathrm{O}$.

Both experiments gave $19 \cdot 66$ per cent. $\mathrm{H}_{2} \mathrm{O}$ instead of $19 \cdot 67$.

Selenate of Samarium, $\mathrm{Sm}_{2}\left(\mathrm{SeO}_{4}\right)_{3}+8 \mathrm{H}_{2} \mathrm{O}$, is easily soluble in water, but in other respects resembles the sulphate.

0.9881 gram lost by careful heating over the open fire, 0.1642 gram, and left by heating to white-red, 0.3951 gram $\mathrm{Sm}_{2} \mathrm{O}_{3}$.

Sulphate of Samarium and Potassium, $2 \mathrm{Sm}_{2}\left(\mathrm{SO}_{4}\right)_{3}+9 \mathrm{~K}_{2} \mathrm{SO}_{4}$ $+3 \mathrm{H}_{2} \mathrm{O}$, was slowly deposited as a white powder, when acetate of samarium was added to an excess of sulphate of potassium. It is very little soluble in a saturated solution of sulphate of potash. It is difficult to state in figures the solubility, as it seems to be much dependent on the temperature and the more or less quantity of free acid present. I have generally found that 1 litre of the saturated solution contains about $\frac{1}{2}$ gram of samarium oxide. 
1.2545 grams lost by heating 0.0246 gram $\mathrm{H}_{2} \mathrm{O}$ (hygroscopic?). The anhydrous salt was dissolved in water, acidulated with $\mathrm{HCl}$, and precipitated with ammonia. The basic sulphate was again dissolved and precipitated. The solutions were evaporated, and gave 0.7229 gram $\mathrm{K}_{2} \mathrm{SO}_{4}$. The oxide of samarium, precipitated as oxalate, amounted to 0.3157 gram.

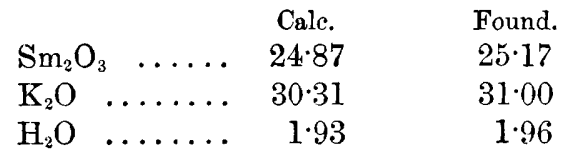

I have before analysed a compound of didymium, having the same composition.

Sulphate of Samarium and Ammonium, $\mathrm{Sm}_{2}\left(\mathrm{NH}_{4}\right)_{2}\left(\mathrm{SO}_{4}\right)_{4}+8 \mathrm{H}_{2} \mathrm{O}$, or $\mathrm{Sm}_{2}\left(\mathrm{SO}_{4}\right)_{3}\left(\mathrm{NH}_{4}\right)_{2} \mathrm{SO}_{4}+8 \mathrm{H}_{2} \mathrm{O}$, crystallises from the mixed solutions of the simple sulphates containing excess of ammonium sulphate, in small tabular crystals.

0.7168 gram lost by $110^{\circ} 0.0935$ gram $\mathrm{H}_{2} \mathrm{O}$, and left by heating to white-red, 0.2888 gram $\mathrm{Sm}_{2} \mathrm{O}_{3}$.

$\begin{array}{llll} & & \text { Calc. } & \text { Found. } \\ \mathrm{Sm}_{2} \mathrm{O}_{3} & \ldots \ldots & 40 \cdot 28 & 40 \cdot 29 \\ \mathrm{H}_{2} \mathrm{O}\left(\frac{6}{8}\right) \ldots \ldots & 12 \cdot 50 & 13 \cdot 04\end{array}$

Selenite of Samarium, $\mathrm{Sm}_{2} \mathrm{O}_{3}, 4 \mathrm{SeO}_{2}+5 \mathrm{H}_{2} \mathrm{O}$, was thrown down by addition of selenious acid to the solution of the acetate, as a bulky precipitate, which was very soon transformed into microscopic needles.

0.8312 gram lost by $110^{\circ} 0.0523$ gram $\mathrm{H}_{2} \mathrm{O}$, and gave 0.2935 gram $\mathrm{Se}$, and 0.3233 gram $\mathrm{Sm}_{2} \mathrm{O}_{3}$, precipitated as oxalate.

0.8910 gram gave $0.0560 \mathrm{H}_{2} \mathrm{O}, 0.3175$ gram $\mathrm{Se}$, and 0.3465 gram $\mathrm{Sm}_{2} \mathrm{O}_{3}$.

\begin{tabular}{lrr} 
& Calc. & \multicolumn{1}{c}{ Found. } \\
$\mathrm{Sm}_{2} \mathrm{O}_{3} \ldots$ & $39 \cdot 46$ & $38 \cdot 90-38 \cdot 89$ \\
$\mathrm{SeO}_{2} \ldots$ & $50 \cdot 34$ & $49 \cdot 61-50 \cdot 07$ \\
$\mathrm{H}_{2} \mathrm{O}\left(\frac{3}{5}\right) \ldots$ & $6 \cdot 12$ & $6 \cdot 29-6 \cdot 28$
\end{tabular}

Oxalate of Samarium, $\mathrm{Sm}_{2}\left(\mathrm{C}_{2} \mathrm{O}_{4}\right)_{3}+10 \mathrm{H}_{2} \mathrm{O}$, is a white or paleyellowish crystalline precipitate. From concentrated solutions it is first thrown down as a viscid, yellowish mass, which soon hardens.

1.0029 gram lost by $110^{\circ} 0.1516$ gram $\mathrm{H}_{2} \mathrm{O}$, and gave by ignition $0 \cdot 4638$ gram $\mathrm{Sm}_{2} \mathrm{O}_{3}$.

\begin{tabular}{|c|c|c|}
\hline $\mathrm{Sm}_{2} \mathrm{O}_{3}$ & $\begin{array}{c}\text { Calc. } \\
46 \cdot 77\end{array}$ & $\begin{array}{l}\text { Found. } \\
46 \cdot 25\end{array}$ \\
\hline $\mathrm{H}_{2} \mathrm{O}\left(\frac{6}{1} \overline{0}\right)$ & 14.52 & $15 \cdot 12$ \\
\hline
\end{tabular}

The salts of samarium agree closely in composition with the 
didymium salts; and of all elements, samarium is most nearly related to didymium, less closely to the yttria metals, the platinocyanates of the latter being wholly different from the samarium salt, which resembles the corresponding salts of cerium, lanthanum, and didymium. 